\title{
UCS effects on ulceration following fear conditioning
}

WILLIAM L. SAWREY, CALIFORNIA STATE COLLEGE, HAYWARD JAMES M. SAWREY, SAN JOSE STATE COLLEGE

Six groups of animals were given fear conditioning trials while immobilized. Conditioning was at three levels of UCS intensity $(.5 \mathrm{~mA}, 1.5 \mathrm{~mA}$ and $2.5 \mathrm{~mA})$ and two lengths of duration $(.25 \mathrm{sec}$ and $.75 \mathrm{sec})$. Ulceration rate increased as a function of increasing UCS intensity but not UCS duration.

Effects of UCS intensity and duration have been investigated by classical conditioning methods using different responses. In eyelid conditioning, UCS intensity has been found to be directly related to speed of acquisition and level of performance (Spence \& Platt, 1966). In GSR conditioning, UCS intensity was directly related to higher response level and greater resistance to extinction (Wickens \& Harding, 1965).

The duration of UCS has been varied when GSR was used as a conditioned response (Bitterman, Reed \& Kranskopf, 1952), in investigating conditioned eyelid reflex (Runquist \& Spence, 1959), and in cardiac conditioning (Wegner \& Zeaman, 1958). The effect of duration of UCS generally has been reported as being negligible. However, Overmier (1966) reports that UCS duration does effect fear conditioning when fear is measured by an instrumental response. It is interesting to note that Overmier indicates there were no differences between short and long duration UCSs when heart rate was the measure taken. His UCS durations were extreme in that they were $.5 \mathrm{sec}$ and $50 \mathrm{sec}$ of intensive shock. It may be that UCS duration must be considerable in order to have a substantial effect. In classical fear conditioning, using an instrumental response as the measure of fear Mowrer and Solomon (1954) report that the bar pressing response did not vary significantly (only .10 level of significance) with UCS durations of 3 and $10 \mathrm{sec}$.

The typical procedure in fear conditioning has been to use a classical conditioning paradigm with an instrumental measure of strength of inferred fear. The present investigation is an attempt to classically condition fear and measure its consequences with a more direct physiological response. The parameters of the UCS involved are intensity and duration. The measure of inferred fear is rate of ulceration. Ulceration rate has been demonstrated to be a function of number of fear conditioning trials previous to CS exposure during restraint (Sawrey \& Sawrey, 1964).

Method

Subjects. The Ss were 66 male, Sprague-Dawley rats, approximately 120 days of age.

Apparatus. Ss were restrained by wrapping them in $1 / 4$ in. wire mesh which formed a cylinder. Nine brass rods were inserted through the mesh to complete the immobilization of $\mathrm{S}$. Shock source was a constant current Applegate stimulator. CS was a $100 \mathrm{~W}$ lamp placed $3 \mathrm{ft}$ in front of the Ss.

Delivery of CS and UCS was controlled by a series of Hunter interval timers.

Procedure. Ss were randomly assigned to one of six experimental conditions. The groups were composed of three levels of UCS intensity $(.5 \mathrm{~mA}, 1.5 \mathrm{~mA}, 2.5 \mathrm{~mA})$ and two durations of UCS presentation (.25 sec and $.75 \mathrm{sec})$.

The procedure was identical for all six groups except for the deliberate variation of UCS intensity and duration. All Ss were food deprived for $24 \mathrm{~h}$ previous to being placed in restraint. Immediately after restraint, copper electrodes were taped to the pads of the rear feet and conditioning was started. Electrodes were taped to the pads to insure the UCS was unavoidable for the appropriate durations and intensities. The conditioning procedure was as follows: The CS of light was presented for $5 \mathrm{sec}$ and was immediately followed by the UCS. Eighty CS trials were administered and a random $40 \mathrm{CS}$ were followed by the appropriate UCS (i.e., .25 sec or $.75 \mathrm{sec})$. The intertrial interval varied randomly between 175 and 285 sec. S were left in restraint following the conditioning procedure for the remainder of a $48 \mathrm{~h}$ period. During the period of restraint following conditioning, the CS was administered every 230 sec. Following restraint Ss were sacrificed, autopsied, and stomach ulcers counted.

Results

The mean number of ulcers for the three intensities were $3.77,6.63$, and 10.72 for $.5 \mathrm{~mA}, 1.5 \mathrm{~mA}, 2.5 \mathrm{~mA}$ respectively. The means for duration were 6.36 and 7.72 for .25 sec and $.75 \mathrm{sec}$ respectively. Ulceration rate increased as intensity of the UCS increased ( $F=3.99$, df $=2.52, p<.05$ ).

Duration and interaction effects were not significant. Discussion

Ulceration rate in a classical fear conditioning situation may be the result of the intensity of the UCS per se rather than a result of the pairing of CS-UCS during conditioning. The finding that ulceration rate does vary with UCS intensity probably can be accounted for, in large part, by the conditioned fear resulting from the CS-UCS pairings. Ulceration presumably results from prolonged gastric secretion. The entire conditioning procedure took place within a $4 \mathrm{~h}$ period of time followed by $44 \mathrm{~h}$ of CS exposureand restraint. It would seem that conditioning deriving from the CS-UCS pairing and the 
subsequent exposure to the CS were responsible for most of the obtained differences. Other findings from this laboratory tend to confirm this conclusion.

The results of this investigation are consistent with other conditioning investigations in supporting the importance of the intensity of the UCS in classical procedures and in indicating, within the durations studied, the negligible influence of duration of UCS. In the current investigation both UCS intensity and duration were insured through the taping of electrodes to the pads. Most previous fear conditioning studies have employed grid shock. Such a procedure leaves the question of duration of an aversive stimulus indecisively answered.

The use of ulceration rate as a dependent variable in fear conditioning appears to provide a more direct measure of strength of fear conditioning than would strength of a subsequently learned instrumental response. This is made even more plausible in view of the conditioning of HCL secretion as reported by Bykov (1957).

References

BITTERMAN, M. E., REED, P., \& KRANSKOPF, J. The effect of duration of the unconditioned stimulus upon conditioning and extinc- tion. Amer. J. Psychol., 1952, 65, 256-262.

BYKOV, K. M. The central cortex and the internal organs. (W. H. Gantt, editor and translator). New York: Chemical Publishing Company, 1957.

MOWRER, O. H., \& SOLOMON, L. M. Contiguity vs. drive-reduction in conditioned fear; the proximity and abruptness of drive-reduction. Amer. J. Psychol, 1954, 67, 15-25.

OVERMIER, J. B. Instrumental and cardiac indices of Pavlovian conditioning as a function of US duration. J. Comp. Physiol. Psychol, $1966,62,15-20$.

RUNQUIST, W. N., \& SPENCE, K. W. Performance in eyelid conditioning related to changes in muscular tension and physiological measures of emotionality. J. exp. Psychol, 1959, 58, 417-422.

SAWREY, W. L., \& SAWREY, J. M. Conditioned fear and restraint in ulceration. J. Comp. Physiol. Psychol, 1964, 57, 150-151.

SPENCE, K. W., \& PLATT, J. R. UCS intensity and performance in eyelid conditioning. Psychol. Bull, 1966, 65, 1-10.

WEGNER, N., \& ZEAMAN, D. Strength of cardiac CRs with varying unconditioned stimulus durations. Psychol Rev., 1958, 65, 238-241.

WICKENS, D. D., \& HARDING, G. B. Effects of UCS strength on GSR conditioning: A within-subject design. J. exp. Psychol, 1965, 70, 151-153.

\section{Note}

1. This investigation was supported by Research Grant M- 5287 from the National Institute of Mental Health, United States Public Health Service and by a creative leave to the first author from the Trustees of the California State Colleges. 